resources to feed it, and an internal need for adjustments to the changed scale and kind of activities. In solving the innumerable problems, external and internal, incidental to such growth and change, it was invaluable to have at hand a man of Stamp's humanity, justice and breadth of understanding. I remember well more than one question of policy or of important personal choice on which the power to rely upon him to come in and give judgment was of first-rate importance. His handling of problems was so transparently honest and so sympathetic to all the different arguments presented to him, that, however he decided any issue in dispute, those who were unsuccessful went away feeling little less happy than those who had succeeded. They were made able to feel, not that they had had a bad case, but that they had had a good case which had unfor. tunately encountered a rather better case on the other side. I have often felt, as so many others have felt, that if there was something affecting us which ought to be decided by someone other than ourselves, we would sooner have Stamp decide it than anyone else of our acquaintance. It was this gift of conciliation, of never quarrelling, even in disagreement, that made Stamp seem the indispensable person for so many important tasks of statesmanship and made him perform so well all those varied tasks.

William Beveridge.

\section{Prof. Herbert Freundlich, For. Mem. R.S.}

$\mathrm{B}^{\mathrm{Y}}$ the death of Herbert Freundlich in Minnesota on March 29 at the age of sixty-one, colloid science has lost one of its chief exponents. His remarkably comprehensive grasp of the literature of what had been up to his time a somewhat widely diffused collection of facts and ad hoc hypotheses permitted him to bring them into order and, indeed, into a logical system. His memory will long survive not only on account of his own contributions, but especially for "Kapillarchemie", his classical book on the subject, of which the fourth edition in two volumes appeared in 1930 .

There are two predominant characteristics which we associate with Freundlich : the simplicity of his experimental technique, and his great influence as a teacher and inculcator of enthusiasm. It is a remarkable tribute to Freundlich that most of the important monographs on the specialized fields in colloid science which have appeared in the last twenty years have been written by authors who commenced their investigations with him. Whilst it is fairly customary for senior research men to spend some time in foreign universities, the particular piece of research work they carry out there is not often chosen as the main field of their future investigations, yet such was the case in the Dahlem Laboratory.

Freundlich's early work on colloid systems dealt with the preparation and coagulation of sols. Whilst this work covered much the same ground that Sir William Hardy had sketched out some years before, it led Freundlich to a more detailed examination of the various properties which sols can acquire in special circumstances. The general principles of the electric double layer had been laid down by Helmholtz and Smoluchowski : Freundlich was the first to show that the so-called electrokinetic (or Freund. lich) potential was an entity distinct from the Nernst or thermodynamic potential, and by a series of im. portant and interesting experiments he showed how variations in the electrokinetic potential and the concomitant change in colloid stability could be produced by the addition of electrolytes. He likewise examined and explained the mechanism of sensitization such as is noted in many biologically important systems and is readily demonstrated by the addition of albumin to a ferric oxide sol.

In 1923 Szegvary showed that a ferric oxide sol to which is added a suitable quantity of electrolyte sets to a gel which can be liquefied by shaking and resets to a lyogel on standing. This behaviour, termed 'thixotropy', was examined in detail by Freundlich, who showed that the same laws apply to thixotropic setting as in electrolytic coagulation, and that a variety of systems, including a number of great technical importance, such as the paints, can exhibit the phenomenon. In investigations which spread over many years, he showed that thixotropic systems are complementary to the dilatant systems of Osborn Reynolds, with a range of plasticity in between. The investigation of the phenomenon of streaming double refraction shown by sols of anisodimensional particles was another important investigation taken up with all the thoroughness and simplicity of experiment characteristic of Freundlich together with his coworker, Zocher.

Among many other investigations initiated by Freundlich, the inquiry with Posnjak into the nature of swelling and the investigations on orientated adsorption in relation to catalytic activity must be mentioned as being especially interesting and suggestive. The adsorption isotherm, usually attributed to Freundlich, was in fact proposed and utilized by Boedeker and Wilhelm Ostwald, but Freundlich greatly extended its application, especially to capillary active solutions.

Freundlich was half British by birth; he had many friends both in Great Britain and in the United States. Those of us who knew him well miss a colleague who was not only erudite, but also at the same time both extremely lively and interesting in conversation.

ERIC K. RideaL.

I ENTERED Freundlich's laboratory in Braun. schweig, where he was professor on the Technische Hochschule, in 1911, working there and later in my own laboratory until the War of 1914-18. Shortly after the War, I translated his great work on colloid chemistry ; the second edition, about twice as long, has found no publisher in English. Froundlich in those days was very happily married to a beautiful Rheinlaenderin with the dark curly hair and blue eyes of the Celtic type so common in those parts. She was a brilliant pianist, as was Freundlich himself, for he had up to the age of nineteen pursued music as a career with the thoroughness and energy characteristic of his family. When he concluded that he 